\title{
Atividades Parentais na Família Monoparental Constituída pela Adoção
}

\author{
Carolina Monteiro Biasutti* \\ Universidade Federal do Espírito Santo - UFES, Vitória, ES, Brasil \\ ORCID: https://orcid.org/0000-0003-2680-6793 \\ Célia Regina Rangel Nascimento** \\ Universidade Federal do Espírito Santo - UFES, Vitória, ES, Brasil \\ ORCID: https://orcid.org/0000-0003-4636-0848 \\ Cláudia Patrocinio Pedroza Canal*** \\ Universidade Federal do Espírito Santo - UFES, Vitória, ES, Brasil \\ ORCID: https://orcid.org/0000-0003-4235-1282
}

\begin{abstract}
RESUMO
O objetivo desta pesquisa foi descrever como pais que passaram pelo processo de adoção monoparental desenvolvem, em sua rotina com os filhos, as atividades parentais de cuidado, controle e desenvolvimento. Foram entrevistados um pai e quatro mães, cuja monoparentalidade adotiva foi uma escolha pessoal. O instrumento utilizado para coleta foi um roteiro de entrevista semiestruturada. A organização dos dados foi realizada com o referencial da Análise Temática e foi fundamentada a partir do Modelo da Parentalidade proposto por Hoghughi. Os resultados foram distribuídos nos temas Cuidado físico, Cuidado emocional, Cuidado social, Controle e Desenvolvimento, que abarcam o grupo das Atividades Parentais. Observou-se que os participantes realizavam interações cotidianas de cuidado, com demonstrações de atenção e afeto para com as crianças, incentivando-as a alcançar seu potencial, buscando atividades complementares para o seu desenvolvimento, bem como estabelecendo regras e limites com a criança em suas práticas educativas parentais. A participação de familiares compôs expressiva rede de apoio nos cuidados com as crianças. Este estudo contribuiu para ampliar a compreensão sobre as práticas parentais exercidas nas famílias monoparentais adotivas por opção, constatando que a parentalidade foi experienciada de forma positiva, constituindo-se numa prática promotora de desenvolvimento tanto para as crianças como para os pais.
\end{abstract}

Palavras-chave: parentalidade, práticas parentais, cuidado da criança, relações familiares, adoção.

\section{Parenting Activities in the Single-parent Family Constituted by Adoption}

\begin{abstract}
The aim of this research was to describe how parents who went through single parent adoption process are performing on their routine the caring, control and development parenting activities with their children. Were interviewed one father and four mothers, whose single parent adoption was a personal choice. The method used to collect the data was a semi-
\end{abstract}

ISSN $1808-4281$ 
structured interview guide. The data organization was made with the reference of Thematic Analysis and data analysis was based on the Model of Parenting proposed by Hoghughi. The results were distributed in the themes Physical-care, Emotional-care, Social-care, Control, and Development, which encompass the group of Parenting Activities. It was observed that the participants reported daily, ongoing and mutual interactions with their children, with expressions of care and affection, encouraging them to reach their potential, seeking complementary activities for their development, as well as establishing rules and limits with the children on their educational parenting practices. The participation of family members made up an expressive support network in the care of children. This study contributed to broaden the understanding of parenting practices exercised by single-parent adoptive families, verifying that parenting was experienced in a positive way, constituting a practice that promotes development for both children and parents.

Keywords: parenting, parental practices, child care, family relationships, adoption.

\section{Actividades Parentales en la Familia Monoparental Constituida por la}

\section{Adopción}

\section{RESUMEN}

Este estudio tiene la finalidad de describir como padres que pasaron por el proceso de adopción monoparental desarrollan en su rutina con los hijos las actividades parentales de cuidado, control y desarrollo. Se ha entrevistado un padre y cuatro madres, cuya monoparentalidad adoptiva fue una elección personal. El instrumento utilizado para la recolección fue un guión de entrevista semiestructurado. La organización de los datos fue realizada con el referencial del Análisis Temático y el análisis de los resultados se basó en el Modelo de la Parentalidad, propuesto por Hoghughi. Los resultados se distribuyeron en los temas Cuidado físico, Cuidado emocional, Cuidado social, Control y Desarrollo, que abarcan el grupo de Actividades Parentales. Se observó que los participantes realizan interacciones cotidianas de cuidado, con demostraciones de atención y afecto hacia los niños, incentivándolos a alcanzar su potencial, buscando actividades complementarias para su desarrollo, así como establecer reglas y límites con el niño en sus prácticas educativas parentales. La participación de los miembros de la familia formó una red de apoyo expresivo en el cuidado de los niños. Este estudio contribuyó a ampliar la comprensión de las prácticas parentales ejercidas por las familias adoptivas monoparentales, verificando que la crianza de los hijos se experimentó de manera positiva, constituyendo una práctica que promueve el desarrollo tanto de los niños como de los padres.

Palabras clave: parentalidad, prácticas parentales, cuidado del niño, relaciones familiares, adopción. 
Embora ainda se encontre na sociedade atual a crença de que a família nuclear, formada por pai, mãe e filhos, seja a ideal para o desenvolvimento de seus membros (Santos, Scorsolini-Comin, \& Santos, 2013), esse padrão tem sido questionado. Famílias monoparentais, homoparentais, recompostas, bem como outros possíveis arranjos, têm adquirido cada vez mais visibilidade, o que tem ampliado o conceito de família no sentido de abarcar essas várias possibilidades (Correa, Minetto, \& Crepaldi, 2018; Santos et al., 2013; Walsh, 2016). Nessa perspectiva, Dessen (2010) analisa que uma definição contemporânea de família vai além dos vínculos consanguíneos e habitacionais entre os seus membros, levandose em conta os laços afetivos estabelecidos entre eles e sua opinião a respeito de quem consideram parte da família.

Em relação às famílias monoparentais, verifica-se que as constituídas por escolha própria tiveram crescimento significativo reportado a partir da década de 1970 (Shireman \& Johnson, 1985). Embora não explore a origem das famílias, o Censo de 2010 no Brasil mostra que houve aumento desse arranjo familiar. No período do levantamento, 16\% das famílias brasileiras eram constituídas por famílias monoparentais femininas e 2,4\% por famílias monoparentais masculinas, um ponto percentual a mais do que o demonstrado no censo de 2000, que eram de 15,3\% e 1,9\%, respectivamente (Instituto Brasileiro de Geografia e Estatísticas [IBGE], 2010). Esse fato tem relação com mudanças sociais, econômicas e tecnológicas ocorridas, com o movimento feminista, a participação da mulher no mercado de trabalho, o aumento do número de divórcios, o uso de métodos contraceptivos que possibilitaram à mulher o planejamento familiar (Arrais, Gomes, \& Campos, 2019; Mannis, 1999; Walsh, 2016), e adiciona-se o desenvolvimento de técnicas de reprodução assistida, além das mudanças nas leis de adoção (Leão, Porta, Pauli, Antoniazzi, \& Siqueira, 2017; Rúbio \& Pérez, 2012). Sendo assim, uma das possibilidades para a formação de uma família monoparental é por meio da adoção de uma criança por uma pessoa solteira. No artigo $n^{\circ} 42$ da primeira versão do Estatuto da Criança e do Adolescente (Lei Federal n. 8.069, 1990), indica-se que qualquer pessoa maior de 21 anos pode entrar com pedido de adoção, independentemente do estado civil. Em 2009, com a Lei Federal n. 12.010 (2009), conhecida como Nova Lei da Adoção, a questão da idade do adotante é modificada para acima de 18 anos, também independente do estado civil.

De acordo com Mannis (1999), inicialmente os estudos sobre a monoparentalidade focavam na crença de déficit associada à falta do par conjugal e no prejuízo causado ao desenvolvimento das crianças. Contudo, a literatura atual (Golombok, 2015; Lamb, 2012; Walsh, 2016) aponta que a monoparentalidade não é, por sua configuração, indicadora de 
desajustes no desenvolvimento da criança e do adolescente, sendo o risco associado a outros fatores, como relações abusivas, limitação de recursos, entre outros.

No estudo de Rúbio e Pérez (2012), de 52 mulheres de famílias monoparentais entrevistadas, 33 optaram pela adoção. Os autores destacam a escassez de artigos relacionados à monoparentalidade por opção, levantando que em muitos trabalhos a família monoparental não é diferenciada em suas peculiaridades. Em revisão sobre a monoparentalidade por opção, Arrais, Gomes e Campos (2019) buscaram estudar a escolha pela monoparentalidade. De 20 artigos encontrados, 14 foram realizados com levantamento direto com participantes, sendo apenas um artigo brasileiro, mostrando que ainda há poucos estudos sobre o tema. Em revisão assistemática de literatura realizada sobre maternidade, adoção e monoparentalidade, Leão et al. (2017) mostraram que estudos sobre o tema têm buscado avaliar as motivações para a adoção, o perfil das famílias, o relacionamento familiar, dificuldades e rede de apoio, bem como aspectos do desenvolvimento dos filhos nessa composição familiar. Assim, acrescentase que um dos aspectos relacionados à família monoparental por opção que deve ser mais bem compreendido diz respeito ao exercício da parentalidade constituída a partir da adoção.

A parentalidade, para Hoghughi (2004), indica um processo de interação positiva que ocorre normalmente entre adultos e crianças, e que envolve atividades de cuidado, carinho e educação. Baseado nas propostas de Bronfenbrenner (1979), Beslky (1984) e Furstenberg (1985), o autor propõe um modelo conceitual com onze dimensões da parentalidade divididas em três grupos de competências: (1) Áreas Funcionais: principais características e aspectos do funcionamento da criança que requerem cuidado, no que diz respeito ao desenvolvimento físico, emocional e intelectual e ao comportamento social; (2) Pré-Requisitos: características dos pais necessárias para o exercício e manutenção das práticas parentais; e (3) Atividades Parentais: conjunto de atividades realizadas pelo cuidador que garantem o bem-estar e a sobrevivência da criança. Essas dimensões são interligadas, demonstrando os processos, atividades e relações que seriam adequadas para avaliar a capacidade e competência parental.

No presente estudo, foi analisado o grupo das Atividades Parentais, com as dimensões: cuidado (físico, emocional e social); controle; e desenvolvimento. Essas dimensões são atividades exercidas pelo adulto, variam de acordo com a idade e a cultura na qual a família está inserida, com objetivo de promover o bem-estar e atender às necessidades de sobrevivência da criança através da prevenção de adversidades que a ameace e da promoção de um desenvolvimento positivo que a auxilie (Hoghughi, 2004).

De acordo com Hoghughi (2004), o cuidado físico envolve a garantia de que as necessidades básicas da criança sejam atendidas para garantir a sobrevivência, como 
alimentação, sono, afeto, vestimenta, saúde e prevenção de danos. O cuidado emocional consiste em assegurar que a criança esteja bem, e demonstrar que esta é amada e respeitada em sua individualidade. Pressupõe que os adultos permitam que a criança tenha a oportunidade de fazer escolhas e correr riscos, estabelecendo interações positivas com o ambiente, deixando-a mais segura para explorar novas situações e desenvolver sua autonomia. Compreende-se que essas práticas proporcionam um melhor desenvolvimento infantil, uma vez que auxiliam na estabilidade emocional da criança, fazendo com que esta seja mais segura frente a novas situações e ajudando-a nas interações com diferentes pessoas e contextos. $\mathrm{O}$ cuidado social visa à integração adequada da criança aos grupos sociais, dando a ela a oportunidade de conviver e trocar experiências com pares, bem como com adultos significativos à criança. Já a dimensão controle, para o autor, consiste nas atividades que os cuidadores desempenham com a intenção de educar as crianças, colocando limites em certas situações, enquanto a dimensão desenvolvimento se caracteriza pelo desejo e incentivo dos pais para que as crianças alcancem seu potencial máximo (Hoghughi, 2004). Essa dimensão está relacionada a como os cuidadores garantem aos membros da família o acesso às informações e atividades necessárias para o melhor aproveitamento de suas capacidades. Hoghughi (2004) indica também como importante tarefa dos pais desenvolver em seus filhos a noção dos valores, tais como curiosidade, tolerância, respeito ao próximo, sabedoria, etc. Tendo em consideração esses pressupostos, o objetivo desse estudo é descrever como as mães e os pais solteiros, que passaram pelo processo adotivo, desenvolvem em sua rotina com seus filhos as atividades parentais de cuidado, controle e de desenvolvimento.

\section{Método}

A pesquisa se caracteriza por ser qualitativa, de caráter exploratório, tendo sido realizado um estudo de casos múltiplos.

\section{Participantes}

Foram entrevistados cinco participantes - um pai e quatro mães, com idades entre $31 \mathrm{e}$ 56 anos, que adotaram seus filhos sozinhos, permanecendo antes e durante a pesquisa nessa condição. Os filhos, dois meninos e três meninas, tinham entre três e doze anos no momento da entrevista. Como critério de inclusão foi estabelecido que esses pais tivessem pelo menos um(a) filho(a), de até doze anos, adotado legalmente e em convivência com a família há no 
mínimo um ano. A renda familiar dos participantes variou de dois a quinze salários mínimos, sendo que quatro famílias viviam com mais de cinco salários. O contato com um dos participantes se deu a partir de solicitação de auxílio nas Varas de Infância e Juventude da região da Grande Vitória, e os outros quatro participantes foram acessados por meio de divulgação do estudo nas redes sociais das pesquisadoras.

\section{Instrumentos}

Utilizou-se um roteiro de entrevista semiestruturada organizado com base em investigações similares, com temas referentes à adoção, educação e parentalidade (Chaves, 2002; Borges, 2010; Merçon-Vargas, 2012; Schettini, 2007) bem como nas dimensões da parentalidade propostas por Hoghughi (2004). Nesse artigo foram utilizados os resultados relativos à caracterização das famílias, às práticas parentais com os filhos e à parentalidade.

\section{Procedimentos e Análise de Dados}

As entrevistas foram realizadas individualmente, no local de preferência do participante, tendo duração média de 144 minutos. Foram gravadas e literalmente e integralmente transcritas para análise. A organização dos dados foi realizada com o referencial da Análise Temática (Braun \& Clarke, 2006) e a análise dos resultados foi referenciada no Modelo de Parentalidade de Hoghughi (2004). Os resultados foram organizados em categorias definidas a priori, considerando as dimensões das Atividades Parentais: cuidado físico, cuidado emocional, cuidado social, controle e desenvolvimento.

A pesquisa foi aprovada pelo Comitê de Ética em Pesquisa com Seres Humanos da Universidade Federal do Espírito Santo, sob o número CAAE 44931415.7.0000.5542, e foi realizada de acordo com os preceitos indicados com as normas previstas na Resolução 466/2012 do Conselho Nacional de Saúde, tendo todos os participantes assinado o Termo de Consentimento Livre e Esclarecido. Foram atribuídos nomes fictícios aos participantes, em que os nomes do pai e das mães têm início com a letra $\mathrm{A}$, enquanto os nomes das crianças se iniciam com a letra $\mathrm{C}$. 


\section{Resultados e Discussão}

Para uma melhor compreensão dos resultados, será apresentada uma breve história de cada família. Em seguida, os resultados sobre o exercício da parentalidade serão descritos em temas organizados a partir de como os cuidadores desenvolviam as atividades parentais de cuidados físico, emocional e social, controle e desenvolvimento.

Caso 1. Arthur e Caio: Arthur era funcionário público e tinha 51 anos de idade. Ele e o filho moravam no andar superior de uma casa geminada, dividida com sua irmã e seu cunhado. Arthur iniciou o processo de adoção pela Vara de Infância e Juventude (VIJ), entretanto, Caio chegou através de uma amiga, que teve conhecimento de uma criança que havia sido abandonada após o parto em outro Estado. Aos 41 anos Arthur adotou Caio, que tinha um dia de vida. No período da pesquisa o menino tinha 10 anos de idade.

Caso 2. Ana e Carlos: Ana era funcionária pública e tinha 56 anos. Ana conheceu Carlos e seu irmão, que tinham quatro e sete anos de idade, em um projeto de apadrinhamento afetivo no Natal de 2006. Ao se envolver cada vez mais com as crianças, buscou a família que adotara uma das irmãs dos meninos. Esta família decidiu adotar também o outro irmão, enquanto Ana iniciou o processo de adoção de Carlos, quando ele tinha cinco anos. No momento da entrevista Carlos estava com 12 anos.

Caso 3. Alice e Cecília: Alice era médica e tinha 35 anos. Ela e a filha moravam com os pais de Alice. A adoção aconteceu através do contato da equipe da VIJ sobre a possibilidade de adoção de uma bebê de dez meses, saudável, porém em acompanhamento médico por ser filha de genitora portadora do vírus HIV. Cecília estava com 11 meses quando adotada, e possuía três anos no momento da entrevista.

Caso 4. Amanda e Cíntia: Amanda era funcionária pública e estava com 31 anos. Amanda e sua filha, de seis anos, moravam no edifício da família, em um apartamento no andar superior ao da mãe. Amanda recebeu uma ligação da VIJ para conhecer Cíntia, e a adotou ao completar um ano de idade. Cíntia estava com seis anos na ocasião da entrevista.

Caso 5. Angélica e Clarice: Angélica era funcionária pública e professora, e estava com 44 anos. Mãe e filha dividiam residência com a avó, o avô e a tia da criança. Angélica foi contatada pela VIJ para conhecer Clarice aos dois meses de vida. Esta encontrava-se no hospital e tinha o diagnóstico de hidrocefalia benigna da infância, tendo realizado uma drenagem cerebral. Na ocasião da entrevista, Clarice estava com quatro anos.

Cuidados Físicos: As famílias apontaram as mudanças ocorridas envolvendo a rotina de cuidados básicos após a chegada da criança. Os participantes relataram preocupar-se com a 
rotina de alimentação da criança, sobretudo se atentando para quais alimentos eram oferecidos aos filhos. As mães e o pai relataram que o café da manhã era uma refeição compartilhada entre eles e os filhos, contudo as quatro mães descreveram que o almoço das crianças era preparado e administrado por outra pessoa, como avós, funcionária ou acontecia na escola. Apenas o pai relatou que ele e o filho faziam todas as refeições diárias em conjunto.

Todos os participantes expuseram que mantinham participação nos hábitos de higiene na rotina com a criança, como dar banho, escovar os dentes, ajudar a criança a usar o banheiro. Três participantes descreveram também que arrumavam a criança para escola e outras situações. Dois participantes, cujos filhos já se arrumavam sozinhos, por terem dez e doze anos, relataram participar desse momento de cuidado lavando, passando e deixando a roupa pronta para a criança vestir. A preocupação em manter uma rotina de sono com os filhos também apareceu no relato de quatro participantes, tendo as crianças um horário específico para dormir e também para acordar. Uma das mães, contudo, tinha mais flexibilidade nesse quesito, pois como ela dava aula no período noturno, explicou que a filha dormia mais tarde para esperá-la chegar.

Pode-se considerar que as práticas cotidianas de cuidado apontadas pelos participantes descrevem o envolvimento e a atenção dispendida na relação com as crianças desde o momento de sua inserção na família, cuidado este que, além de garantir o desenvolvimento das crianças, contribui para a formação do vínculo entre os pais e os filhos, conforme explicita o Comitê Científico do Núcleo Ciência Pela Infância (2016):

O cuidado cotidiano de crianças pequenas é fundamental para que elas cresçam e se desenvolvam, para ser fisicamente saudáveis, emocionalmente seguras e respeitadas como sujeitos sociais. No processo de desenvolvimento, a criança necessita de interações positivas e de cuidados adequados, desempenhados por pessoas comprometidas com a sua saúde e bem-estar. (Comitê Científico do Núcleo Ciência Pela Infância, 2016, pp. 5)

A contratação de serviços para auxiliar na rotina ou com aspecto dos cuidados da criança, em algum momento da vida, foi apontada por quatro participantes. Duas mães contaram no passado com a presença de uma funcionária que as auxiliavam com os cuidados com a criança. O participante do sexo masculino relatou ter optado por deixar o filho na creche aos dois meses de idade, por precisar voltar ao trabalho, e outro serviço utilizado como suporte por duas mães foi a contratação de transporte escolar. 
Nas cinco famílias, a família extensa também participava das atividades de cuidados da criança. Duas mães relataram que a rotina de cuidados com as filhas era igualmente compartilhada entre a mãe, os avós e a tia e ainda que, quando estavam ausentes, esses familiares assumiam integralmente as responsabilidades pela criança. Para uma das famílias se estabeleceu uma rotina semanal em que a avó cuidava da criança no período da manhã, e a mãe assumia os cuidados a partir do momento em que a filha voltava da escola. A participante destacou que a avó, que era professora infantil, optou por trabalhar em apenas um turno para assumir essa responsabilidade e poder colaborar nos cuidados com a neta. Outra mãe relatou ter ficado por meses estudando nos Estados Unidos, tendo contado nesse período com os avós, que cuidaram exclusivamente da criança na sua ausência. Outra mãe relatou que naquele ano o filho havia começado a passar as tardes durante a semana na casa da irmã, com a avó. Apenas o pai relatou ter menos ajuda com relação ao filho, contudo, a irmã o auxiliava levando a criança para a escola durante a semana. Dessa forma, todos tinham em algum momento uma rede de apoio na figura dos familiares: [...] eu tenho uma adoção onde eu sou a mãe, mas eu tenho uma avó muito presente, uma tia muito presente, um avô muito presente porque eles fazem todo um suporte de cuidados na minha ausência (Angélica).

A influência da cultura sobre as práticas parentais é discutida por Hoghughi (2004) e envolve a experiência de vida dos pais, a influência de parentes na vida da família, bem como o conhecimento sobre cuidados presentes na cultura na qual a família está inserida. A diversidade de contextos sociais resulta em diferentes práticas culturais que permeiam o desenvolvimento das pessoas nas sociedades, orientando como elas pensam, interpretam e interagem no mundo, o que repercute nos processos de parentalidade vivenciados pelas famílias (Oliva, Pugliese, \& Cindra, 2018). Informações, crenças e hábitos são especialmente difundidos através da transmissão geracional e exercem influência nos cuidados com a criança de uma forma ampla (Oliva et al., 2018; Pêssoa \& Rosa, 2018), influenciando também a avaliação do que é um cuidado considerado adequado para o desenvolvimento da criança numa sociedade ou grupo familiar (Franco \& Szymanski, 2012).

Nesse âmbito, uma vez que se considera que a criança não deve ficar sem a supervisão de um adulto, a rede de apoio composta pela participação de outras pessoas no cotidiano com as crianças assume relevância, especialmente quando os pais/mães trabalham. Assim, a participação mais expressiva da família extensa, particularmente na figura dos avós, no compartilhamento dos cuidados com as crianças, como relatado pelos participantes, tem sido descrita na literatura como uma alternativa na organização da rotina das famílias com filhos (Cardoso \& Brito, 2014). 
Em relação aos cuidados com a saúde, três participantes apontaram que as filhas foram adotadas com necessidade imediata de atenção médica, e que ainda faziam acompanhamento médico periódico até o momento da entrevista. Apenas o pai relatou ter passado por processos mais graves de saúde com a criança, precisando permanecer com o filho no hospital. Nesses episódios, relatou que procurou a pediatra da criança imediatamente e que ficava ao lado do filho, cuidando para que suas necessidades fossem atendidas, buscando agilizar o diagnóstico e tratamento. Quando questionados sobre a saúde da criança, no período da entrevista, os principais problemas relatados foram gripes, viroses, sinusites e alergias. Três pais enfatizaram que os filhos eram crianças muito saudáveis e que não costumavam ficar doentes. Dois participantes associaram manter uma boa alimentação com ter uma boa saúde.

Acredita-se que a condição socioeconômica e o ambiente de trabalho das famílias entrevistadas no presente estudo proporcionaram maiores oportunidades de buscar auxílio profissional para promover a saúde dos filhos, tendo a chance de sanar suas dúvidas e obter informações nas visitas médicas, além de possuírem maiores conhecimentos acerca das necessidades infantis, fator que pode estar associado ao nível de escolaridade dos pais entrevistados, a orientação recebida por familiares e amigos, entre outras variáveis. A esse respeito, Hoghughi (2004) pondera que, no cuidado, uma das práticas que difere os seres humanos de outras espécies é que esses, quando têm condições, vão além daquilo que seria o necessário para suprir as necessidades básicas da criança, inserindo outros recursos para garantir o que consideram necessário para a saúde dos filhos. Nesse sentido, os pais buscam oferecer ampla variedade de alimentos, diferentes tipos de vestimentas, vão a consultas médicas de rotina e extras, buscam informações e exercem práticas de prevenção de doenças, etc., buscando promover o desenvolvimento dos seus filhos.

Cuidados Emocionais: Os cinco participantes deste estudo relataram trocar experiências afetivas com os filhos, enfatizando a importância de evidenciar à criança o amor e carinho que sentiam por elas, fator que reconheceram ser recíproco, já que os filhos correspondiam às expressões de afeto. Eles relataram expressar carinho aos filhos diariamente na forma de beijos e abraços, bem como por meio de verbalizações, como elogios, demonstração de orgulho e ao dizer que os amavam. Alguns pais apontaram que quando chamavam a atenção e corrigiam os filhos também estavam demonstrando carinho: [...] Não tem um dia que ele não fala, 'pai, eu te amo', e eu adoro (...) eu nunca ouvi do meu pai, 'eu te amo, meu filho', nunca, e eu falo isso todo dia para ele (Arthur).

Em revisão de literatura sobre diferentes configurações familiares, Lamb (2012) destacou que tais práticas são preditoras de um bom ajustamento no relacionamento entre pais 
e criança. Estas expressões de afeto também foram avaliadas em outros estudos sobre a comunicação na relação progenitor-filho, indicando que a existência de afeto facilita o desenvolvimento da comunicação familiar e de competências sociais na criança (Gomide, 2014; Portugal \& Isabel, 2013), e que práticas parentais afetuosas fundamentadas no respeito, carinho, amor e confiança, proporcionam um ambiente mais propício para o bom desenvolvimento da criança e do adolescente (Toni \& Hecavei, 2014).

Sendo assim, de acordo com as práticas parentais exercidas pelos pais, pode-se presumir a qualidade do vínculo entre cuidador e criança. De acordo com Barudy e Dantagnan (2005), é por meio dessas interações que a criança recebe palavras de incentivo e a mensagem de que é aceita e amada incondicionalmente, passando a se sentir segura e pertencente à família. Para o autor, assegurar esse tipo de relação e vínculo proporciona à criança a capacidade de diferenciar-se do outro e ter autonomia, defendendo suas próprias ideias e pensamentos, ao mesmo tempo em que se sente segura do relacionamento e vínculos constituídos com suas figuras de referência.

Ao abordarem diferentes situações envolvidas nas práticas parentais, os participantes demonstraram ter atenção e manter uma relação de proximidade com os filhos, desenvolvendo sensibilidade quanto aos sentimentos das crianças e preocupação em garantir seu bem-estar emocional. Essa predisposição foi demonstrada por Ana mesmo antes da adoção se concretizar. Ela, que adotou o filho após convivência anterior com a criança, expressou que era sempre difícil devolvê-lo à casa de passagem, pois acreditava que seria um fator de estresse para a criança. Ao adotá-lo, deixou claro para o filho que ele não precisaria voltar mais para a instituição. Outra preocupação era preservar a relação do menino com o irmão, assim levava o filho para visitá-lo frequentemente: [...] apesar de ser um momento diferente, essa relação com o irmão (eu) não queria quebrar, [...] não era uma coisa que precisava acabar. (Ana).

Para outra mãe, a percepção sobre os sentimentos da criança foi evidenciada no relato de que a filha tinha uma reação emocional negativa quando precisava ficar distante das pessoas com quem tinha vínculos. A participante avaliou que essa dificuldade tinha relação com a vivência do abandono e com as adaptações que teve que fazer, por ter se mudado para outro país e depois retornado ao Brasil, além da criança ter mudado três vezes de escola, tendo que se adaptar a novos professores, equipe, colegas de sala e também com outro idioma.

Situações vivenciadas pelos filhos quanto à monoparentalidade no contexto da escola também revelaram a percepção e atenção dos participantes em relação aos sentimentos dos filhos: [...] (Cíntia) chegou um dia bem chateada, falando: - 'Eu não tenho pai'. Eu: - 'Não, 
Cíntia, as pessoas são diferentes'. - 'Mas o fulano falou que eu estou mentindo, que todo mundo tem pai'. [...] aí eu tive toda uma conversa com ela e ela entendeu (Amanda).

Simões, Farate, Soares e Dutra (2013) destacam que práticas que envolvem um bom suporte emocional e menor rejeição estão associadas à maior qualidade de apego, tendo impacto positivo no desenvolvimento da criança. No cenário da adoção, pode-se inferir que um bom suporte emocional, com práticas de expressão de cuidados e afeto, auxilia pais e filhos a desenvolverem uma boa vinculação, necessária para que se construa um sentimento de pertencimento que se concretize no dia-a-dia (Bicca \& Grzybowski, 2014).

A questão da adoção emergiu também como tema que revelou a preocupação dos pais com a integridade emocional dos filhos. Todos consideravam a adoção como algo natural e buscavam conversar com os filhos sobre o tema. Duas participantes acrescentaram ter deixado explícito para as filhas que foram muito desejadas, e outras duas trabalharam com as crianças a ideia de que não vieram da barriga, mas sim do coração. A mãe que realizou a adoção tardia destacou não ter escondido nada do filho durante o processo de adoção, uma vez que a criança já tinha conhecimento de sua história.

Souza e Miranda (2009) assinalam a importância da sinceridade quanto à origem da criança nas famílias adotivas, destacando que essa conversa envolve o filho em um ambiente de compartilhamento da verdade e de lealdade entre estes e os pais, inserindo-o em um ambiente seguro e confortável. Huber e Siqueira (2010) e Pena (2016) observaram em suas investigações que existem medos e fantasias em torno desse tema para as famílias, por exemplo, sobre como conversar com a criança e sobre a possibilidade de algo dar errado. Além do receio de que a criança deseje buscar a família biológica, revelando o medo dos pais de que os laços de sangue prevaleçam aos laços afetivos, cultivados com a família adotiva.

O sentimento de pertencimento da criança ao núcleo familiar também teve destaque no relato de todos os pais. Três participantes enfatizaram a importância de ter a certidão de nascimento dos filhos em seus nomes, e três ressaltaram a satisfação que sentiram ao perceberem que a criança havia sido incluída na família sem que houvesse diferenças de tratamento. Todos apontaram a importância da aceitação da criança pelos membros de suas famílias e da inserção do filho de forma natural nesse novo contexto.: [...] a gente fez uma festa do papel na escola, levamos bolo e colamos a certidão de nascimento nas paredes de toda a escola [...] (Ana).

Considera-se que a relação filial é afirmada nas vivências diárias dos membros da família em uma diversidade de ambientes sociais e ainda na concretização da adoção legal da criança, ou seja, quando esta passa a dispor do nome da família em seu registro. Acrescenta-se 
que na família biológica a criança se encontra inserida em uma família que já a tem como membro efetivo, enquanto que na adoção, tanto criança quanto pais adquirem a garantia do pertencimento por meio das práticas afetivas entre os membros da família e do reconhecimento da relação filial pela família extensa e pela sociedade (Maux \& Dutra, 2010).

Cuidados Sociais: Todos os participantes relataram que os filhos foram bem acolhidos a partir de sua chegada à família e que os filhos conviviam com frequência com tios e tias e avós e/ou avôs, quando estes existiam na família extensa: [...] Com a avó é muita segurança, tranquilidade, afeto, carinho, cuidado. Ela também põe alguns limites. Com a tia também ela tem uma excelente relação. (Angélica).

Três participantes destacaram ainda que as crianças conviviam com frequência com primos e primas que tinham idades próximas. Uma das mães ressaltou a convivência da família com os irmãos biológicos do filho, descrevendo sentir-se como uma tia para estes. É importante observar que todos os pais descreveram morar ou terem morado em algum momento junto ou próximo a algum familiar. Apenas uma participante já não morava perto da família extensa, contudo por anos residiu no mesmo bairro que a mãe e a família da irmã. Alguns participantes ainda inddicaram situações em que a família extensa participava, além dos cuidados, de atividades de lazer com a criança, como brincar, ir a parques e shoppings, participar de atividades festivas na escola, levar em festas infantis, entre outras atividades.

Verificou-se que as famílias monoparentais deste estudo contaram com o envolvimento e apoio da família extensa para organizar a rotina de cuidados com a criança e sua rotina pessoal de trabalho, destacando-se a convivência das crianças com esses familiares. Essa convivência também foi apontada por outros estudos (Leão et. al., 2017; Shireman \& Johnson, 1985). Um aspecto interessante evidenciado no estudo longitudinal de Shireman e Johnson (1985) com mães adotantes monoparentais, foi que as famílias tendiam a se relacionar mais com a família extensa, quando os filhos tinham por volta de três anos, após as crianças completarem oito anos, ampliaram-se as relações com a comunidade escolar e religiosa.

Com relação ao envolvimento de amigos na vida da família, apenas dois participantes relataram ter experiências frequentes que compunham uma rede de apoio extrafamiliar. Um participante descreveu que sua família era composta pelo filho, irmãs e pelas amigas, e expôs situações em que estas também se envolviam com os cuidados da criança e se adequavam para que a criança pudesse estar presente nas programações.

A convivência da criança com os pares fora do núcleo familiar acontecia principalmente no momento em que estavam na escola, e em menor escala, com vizinhos de 
idades similares. Uma mãe destacou a convivência frequente da filha com um amigo para além do ambiente escolar, por ter se tornado amiga da família da criança. Já os dois participantes em que os filhos tinham entre 10 e 12 anos destacaram oportunizar, com frequência, encontros entre os filhos e colegas de escola e vizinhos. $\mathrm{O}$ pai pontuou permitir que o filho brincasse regularmente com amigos residentes da vizinhança, enquanto uma das mães relatou ter possibilitado alguns encontros mais autônomos entre o filho e os amigos, ao combinar idas ao cinema nas quais buscava o filho ao final.

Machado, Ferreira e Seron (2015) destacam a importância da socialização da criança com outras pessoas que não fazem parte do núcleo familiar, indicando que nessa inserção da criança em outros contextos há a oportunidade desta desenvolver-se adequadamente e aprender as regras sociais presentes na comunidade. Esta vivência deve ser mediada pelos pais que influenciarão a forma da criança se perceber e se situar nas interações e assumir comportamentos na relação com outras pessoas. A dimensão cuidado social é vital para o desenvolvimento do individuo, uma vez que as relações sociais influenciam diretamente na visão que ele tem de si mesmo e do outro (Hoghughi, 2004).

Controle: Em relação às estratégias disciplinadoras nas famílias estudadas, os participantes entrevistados relataram fazer uso do castigo, da punição física, do diálogo e da imposição de limites e regras. Na família de duas participantes, a disciplina era obtida exclusivamente por meio do diálogo. Elas e os filhos estabeleciam alguns acordos nos quais a opinião da criança também era considerada, e quando necessário, exerciam sua autoridade decidindo e expressando o que os filhos deveriam fazer: [...] Então se ela não quer, por que você não quer? [...] às vezes a gente cede, inclusive [...] Eu não quero ser ditadora, mas tem umas coisas que é não e não! (Angélica).

Outros dois participantes mostraram-se mais tradicionais, indicando a palmada como principal recurso para obter a disciplina. O pai relatou utilizar também o diálogo, repetindo, se necessário, até que o filho entendesse. Uma mãe relatou ter estabelecido como método disciplinador um sistema de contagem que parte da idade da criança e faz referência à quantidade de palmadas que a filha recebe caso não mude de comportamento. Ela considerou, entretanto, que poucas são as vezes que a criança a desobedece ou não ajusta o comportamento quando chamada a atenção: [...] dou a contagem, se ela não obedecer, eu tiro o chinelo, e dou cinco chineladas na bunda dela. [...] Não adianta tentar me convencer [...] eu cumpro. (Amanda).

Outra participante mencionou utilizar tanto punição física como o castigo e o diálogo como métodos para disciplinar a filha. Ela relatou deixar a criança mais livre, orientando e 
dialogando sempre que necessário, porém afirmou que em situação que a filha mantém um mau comportamento, o limite é sinalizado com uma palmada e um castigo, momento no qual coloca a filha no quarto para pensar. Quando essa se acalma, conversa com a criança explicando o motivo pelo qual foi para o castigo e responde suas dúvidas. Três pais descreveram que as crianças apresentavam reações de provocações, manha e choro, enquanto outros dois relataram que as crianças tentavam argumentar e questionar as ordens impostas. Uma mãe ainda avaliou que a filha testava os limites de sua autoridade ao solicitar à avó o que já lhe havia sido negado.

Apesar de algumas crianças terem maior dificuldade do que outras com relação à compreensão dos limites, os pais relataram que, de uma maneira geral, as crianças conseguiam compreender, ou ao menos aceitar as regras impostas. Observou-se que as crianças mais novas, obedeciam por entenderem que, caso contrário, sofreriam consequências. Já com as mais velhas, os pais apontaram a capacidade de compreensão das atitudes e reconhecimento do comportamento dos pais, muitas vezes não havendo a necessidade de imposição de regras, provavelmente por reconhecerem os limites e entenderem suas implicações: [...] Eu acho que ele aprende me observando, não extrapola em nada, não é mal-educado, pelo contrário. (Arthur).

Gomide (2014) aponta que é necessário estabelecer regras no dia a dia com a criança, embora segundo a autora estas devam ser poucas e flexíveis, para que os filhos possam efetivamente cumpri-las. De acordo com a autora, os pais ainda devem preocupar-se com a forma escolhida para colocar limites quando uma regra é desrespeitada, uma vez que, se os pais não cumprirem com o planejado, será passada uma mensagem para a criança de insegurança do que é considerado o certo e o errado, e também de que as regras podem ser desacatadas. Esse aspecto foi abordado de forma unânime entre os pais do presente estudo, e todos se mostraram preocupados em cumprir as exigências feitas às crianças.

A socialização na família envolve, entre outras coisas, transmissão de regras, valores e padrões de conduta (Pêssoa \& Rosa, 2018). As práticas utilizadas pelos pais para educar em relação a esses objetivos podem variar ao longo do tempo, do que é considerado adequado ou não numa sociedade e em função de características das pessoas e das famílias, além das condições de vida às quais estão expostas e do período do desenvolvimento dos filhos (Patias, Siqueira, \& Dias, 2013). Atualmente, considera-se que a punição física não é uma estratégia adequada para se colocar limites para a criança, havendo uma maior valorização do diálogo e do desenvolvimento da autonomia da criança (Ribeiro, 2012). É possível ponderar a esse respeito que a palmada faz parte das práticas parentais educativas no Brasil há séculos, sendo 
reproduzida e ensinada através das gerações, e como outras mudanças que ocorreram na família na nossa sociedade, a convivência de novos e velhos valores podem ser observados (Ribeiro, 2012). Quanto a isso, Ribeiro (2012) aponta para a necessidade de se questionar a prática da palmada, mas, sobretudo, para a importância de implementar conversas sobre essa temática com os pais em diferentes contextos, acolhendo suas inseguranças, porém refletindo em conjunto sobre outras possibilidades para que possam compreender e optar por novas maneiras de exercerem o controle parental.

Toni e Hecavei (2014) observaram em seu estudo que práticas educativas envolvendo disciplinas coercitivas, falta de acompanhamento, negligência e punição física, foram relacionadas a menores rendimentos acadêmicos entre as crianças, sendo consideradas preditoras de comportamentos disfuncionais em crianças e adolescentes, como comportamentos agressivos, sentimento de baixa autoeficácia, falta de habilidade em resolver problemas. Já as práticas educativas pautadas na monitoria positiva, na comunicação, no comportamento moral e no afeto entre pais e filhos estavam associadas ao melhor rendimento escolar das crianças, a relacionamentos mais afetuosos entre pais e filhos, fundamentados no respeito, carinho, amor e confiança, comportamentos esses que proporcionam aos filhos um ambiente favorável para o bom desenvolvimento da criança e do adolescente.

De acordo com Gomide (2014), para que a criança cresça e se desenvolva de forma saudável e bem ajustada, deve existir um cuidado dos pais em demonstrar interesse e acompanhamento positivo ao longo das interações com os filhos. Os pais devem demonstrar amor, carinho, respeito pela sua opinião, interesse nos assuntos propostos pela criança, sem desencadeamento de broncas e represálias, mas provocando autorreflexão sobre possíveis atitudes, elogiando seus esforços e conquistas.

Desenvolvimento: Todos os participantes demonstraram cuidado e preocupação com o desenvolvimento dos filhos e evidenciaram oportunizar atividades para que as crianças pudessem adquirir novas competências. Ao descreverem a rotina das crianças, mencionaram atividades extracurriculares realizadas na própria escola ou em outros espaços, consideradas importantes para o desenvolvimento dos filhos. Além de estimular as crianças com jogos e outras atividades, alguns participantes proporcionavam experiências culturais às crianças: [...] A gente vai muito ao teatro, [...] vai a concerto de música... (Ana).

Quatro participantes enfatizaram a necessidade de estimulação da criança ao chegarem à família e demonstraram que continuavam a se preocupar, oferecendo estímulo constante para auxiliá-las no desenvolvimento. Três mães apontaram que em casa as filhas recebiam a atenção e a estimulação de diversos membros da família que interagiam constantemente com 
elas. Apenas o participante que adotou o filho recém-nascido não demonstrou que essa era uma preocupação inicial, já que acompanhou a criança em todas as fases do desenvolvimento e participou de todos os processos de estimulação do filho.

Todos os pais demonstraram acompanhar e incentivar as crianças com relação à escola. Estes assinalaram o apoio às crianças com aulas de reforço, auxilio dos pais, familiares e amigos nos estudos e tarefas escolares. Dois pais explicitaram que cobravam dos filhos um bom desempenho escolar, dialogando com esses sobre a responsabilidade e a importância do estudo. Duas participantes enfatizaram a busca por escolas que ofereciam atividades extracurriculares.

Hoghughi (2004) aponta que ter acesso a recursos econômicos costuma contribuir para que a criança tenha uma promoção adequada de educação, esporte e cultura, embora o sistema público também deva investir em tais áreas para garantir o desenvolvimento de habilidades em toda a população. Considera-se, assim, que crianças com boas oportunidades de desenvolvimento, ampliam suas habilidades e seu potencial é mais bem explorado. O estímulo dos pais é uma prática que favorece esse desenvolvimento. Wade (2004) aponta que o envolvimento dos pais com a evolução escolar dos filhos está associado ao bom desenvolvimento da leitura e melhores resultados escolares.

Três participantes ainda demonstraram preocupação em desenvolver a autonomia das crianças de diferentes maneiras, de acordo com a idade e estágio de desenvolvimento de cada um. Para as mães de duas crianças pequenas, a autonomia foi descrita como sendo possibilitada pelo respeito à opinião da criança. Outra participante relatou que incentivava o filho, que já estava com doze anos, a realizar algumas atividades por conta própria. Uma das mães também relatou incentivar a criança a desenvolver a argumentação no ambiente familiar.: [...] então o tempo todo se falava, 'Clarice, quando você quiser você tem que falar o que você quer' [...] e hoje ela 'Eu não quero isso porque isso, isso e isso', justifica (Angélica). Machado et al. (2015) destacaram que a existência de um ambiente favorecedor, com os estímulos necessários e com pessoas que incentivem a criança, são propiciadores do desenvolvimento saudável da criança, não apenas no aspecto físico e motor, mas também no emocional, proporcionando à essa segurança e autonomia.

Quatro participantes ainda apontaram a importância de ensinar e desenvolver valores nos filhos. Três deles relataram ser importante mostrar às crianças que deveriam respeitar as outras pessoas, bem como o que é do outro: [...] Você gostaria que os outros ficassem mexendo com você??', 'não pai'..., 'então porque você tá fazendo isso com ele?' (Arthur). 
Outro aspecto também destacado por dois participantes foi o preparo que eles deveriam ter para a vida em sociedade. Ambos abordaram a questão da facilidade hoje com que as crianças, de modo geral, obtêm o que desejam, e disseram tentar construir outra forma de lidar com os filhos. Uma participante relatou que tinha consciência de que não deveria dar à filha o que ela quisesse na hora que quisesse, e afirmou que esperava promover na criança o respeito às dificuldades e desafios, além de evitar que se tornasse uma pessoa centralizadora. Já o outro participante disse que conversava com o filho sobre as dificuldades presentes na vida e que as coisas não são conquistadas de uma hora para outra.

Gomide (2014) aponta a importância de se conversar com as crianças, fornecendo materiais que estimulem a discussão de valores morais, como livros, filmes e exemplos reais que possam ser refletidos em um momento de interação entre pais e crianças. A autora ainda acrescenta que a melhor forma de desenvolver comportamentos baseados em condutas assertivas nas crianças é pelo exemplo das atitudes dos próprios pais no cotidiano.

\section{Considerações Finais}

Os estudos sobre parentalidade vêm se intensificando ao longo das últimas décadas e novos aspectos têm sido considerados importantes para a compreensão dessa prática diária. Considerações sobre a relação bidirecional da interação entre pais e filhos, a influência do contexto no qual estão inseridos e ainda a compreensão de que as características e vivências pessoais interagem na atuação parental, fazem parte da ampliação do entendimento da parentalidade (Tudge \& Freitas, 2012).

O presente estudo teve por objetivo conhecer a vivência da parentalidade em famílias adotivas monoparentais, utilizando como referência o Modelo da Parentalidade proposto por Hoghughi (2004). Mais especificamente, foi observado o grupo das Atividades Parentais. De modo geral, os participantes desse estudo relataram interações diárias, contínuas e recíprocas com seus filhos, com demonstrações de cuidado e afeto para com a criança, incentivando-a a alcançar seu potencial, buscando atividades complementares para o seu desenvolvimento, bem como estabelecendo regras e limites em suas práticas educativas parentais. Destacou-se ainda a participação da família extensa, particularmente os avós e tias na divisão de cuidados com as crianças, apoio que se mostra relevante no caso da família com apenas um cuidador principal. Foi possível constatar entre as famílias monoparentais estudadas que a parentalidade foi experienciada de forma positiva e se constituiu numa prática promotora de 
desenvolvimento tanto da criança como dos pais, possibilitando a formação de laços afetivos e duradouros, fornecendo um ambiente adequado para o desenvolvimento das crianças.

Considera-se que esse estudo contribuiu para ampliar o corpo de conhecimento sobre a vivência da parentalidade para famílias monoparentais por opção, constituídas a partir da adoção. Pode-se destacar a análise da parentalidade com o Modelo de Parentalidade de Hoghughi (2004) como sendo uma contribuição para os estudos sobre o tema no Brasil, uma vez que não foram encontrados outros trabalhos com sua utilização.

Por se tratar de um estudo qualitativo de casos múltiplos, dessa forma, com número reduzido de participantes, sugere-se que novos trabalhos sejam realizados no que concerne à família monoparental adotiva e ao processo de adoção e parentalidade, com um número ampliado de participantes, com metodologias qualitativas, quantitativas e/ou mistas, a fim de obter resultados que possam ser generalizados para esse grupo. Sugere-se ainda a investigação da interação das famílias monoparentais em outros espaços de convivência. Espera-se, com este estudo, ter contribuído para ampliar a compreensão sobre as práticas parentais exercidas nas famílias monoparentais adotivas por opção, contribuindo para que essas famílias tenham o apoio da sociedade e dos serviços ligados ao processo da adoção.

\section{Referências}

Arrais, R. H., Gomes, I. C., \& Campos, E. M. P. (2019). A monoparentalidade por opção e seus aspectos psicossociais: Estudo de revisão integrativa. Revista da SPAGESP, 20(1), $39-54$.

Recuperado

de http://pepsic.bvsalud.org/pdf/rspagesp/v20n1/v20n1a04.pdf

Barudy, J., \& Dantagnan, M. (2005). Los buenos tratos a la infancia: Parentalidad, apego y resiliência. Barcelona: Gedisa.

Bicca, A., \& Grzybowski, L. S. (2014). Adoção tardia: Percepções dos adotantes em relação aos períodos iniciais de adaptação. Contextos Clínicos, 7(2), 155-167. doi: $10.4013 /$ ctc. 2014.72 .04

Brasil (1990). Lei Federal n. 8.069, de 13 de julho de 1990. Dispõe sobre o Estatuto da Criança e do Adolescente e dá outras providências. Recuperado de http://www.planalto.gov.br/ccivil_03/leis/18069.htm\#: :text=LEI\%20N\%C2\%BA\%20 8.069\%2C\%20DE\%2013\%20DE\%20JULHO\%20DE\%201990.\&text=Disp\%C3\%B5 e\%20sobre\%20o\%20Estatuto\%20da,Adolescente\%20e\%20d\%C3\%A1\%20outras\%20 provid\%C3\%AAncias.\&text=Art.\%201\%C2\%BA\%20Esta\%20Lei\%20disp\%C3\%B5e 
,\%C3\%A0\%20crian\%C3\%A7a\%20e\%20ao\%20adolescente.\&text=Nos\%20casos $\% 20$ expressos\%20em\%20lei,e\%20um\%20anos\%20de\%20idade

Brasil (2009). Lei Federal n. 12.010, de 3 de agosto de 2009. Dispõe sobre adoção; altera as Leis nos 8.069, de 13 de julho de 1990 - Estatuto da Criança e do Adolescente, 8.560, de 29 de dezembro de 1992; revoga dispositivos da Lei no 10.406, de 10 de janeiro de 2002 - Código Civil, e da Consolidação das Leis do Trabalho - CLT, aprovada pelo Decreto-Lei no 5.452, de 1 o de maio de 1943; e dá outras providências. Recuperado de http://www.planalto.gov.br/ccivil_03/_ato20072010/2009/lei/112010.htm\#: :text=1o\%20Esta\%20Lei\%20disp\%C3\%B5e,da\%20Cria n\%C3\%A7a\%20e\%20do\%20Adolescente

Braun, V., \& Clarke, V. (2006). Using thematic analysis in psychology. Qualitative Research in Psychology, 3(2), 77-101. doi: 10.1191/1478088706qp063oa

Borges, I. C. N. (2010). Qualidade da parentalidade e bem-estar da criança (Dissertação de Mestrado). Faculdade de Psicologia e de Ciências da Educação, Universidade de Coimbra, Coimbra, Portugal. Recuperado de http://hdl.handle.net/10316/15564

Cardoso, A. R., \& Brito, L. M. T. (2014). Ser avó na família contemporânea: Que jeito é esse?. Psico-USF, 19(3), 433-441. doi: 10.1590/1413-82712014019003006

Chaves, V. P. (2002). A interação mãe-criança em famílias adotivas: Um estudo comparativo (Dissertação de Mestrado). Instituto de Psicologia, Universidade Federal do Rio Grande do Sul, Porto Alegre, Brasil. Recuperado de https://lume.ufrgs.br/handle/10183/3049

Comitê Científico do Núcleo Ciência Pela Infância (2016). Estudo $n^{o}$ II: Importância dos vínculos familiares na primeira infância. São Paulo: NCPI. Recuperado de http://www.ncpi.org.br

Correa, W., Minetto, M. F., \& Crepaldi, M. A. (2018). Família como promotora do desenvolvimento de crianças que apresentam atrasos. Pensando famílias, 22(1), 44-58. Recuperado de http://pepsic.bvsalud.org/scielo.php?script=sci_arttext\&pid=S1679494X2018000100005

Dessen, M. A. (2010). Estudando a família em desenvolvimento: Desafios conceituais e teóricos. Psicologia: Ciência e Profissão, 30(spe), 202-219. doi: 10.1590/S141498932010000500010

Franco, F. S., \& Szymanski, H. (2012). Práticas parentais: Um estudo sobre escolhas educativas. Memorandum, 22, 211-225. Recuperado de: 
http://www.fafich.ufmg.br/memorandum/wpcontent/uploads/2012/06/francoszymansk i01.pdf

Golombok, S. (2015). Modern Families: Parents and children in new family forms. Cambridge: Cambridge University Press.

Gomide, P. I. C. (2014). Pais presentes, pais ausentes: Regras e limites (13a ed.). Petrópolis, Rio de Janeiro: Vozes.

Hoghughi, M. (2004). Parenting: An introduction. In M. Hoghughi, \& N. Long (Eds), Handbook of parenting: theory and research for practice (pp. 1-18). London: Sage.

Huber, M. Z., \& Siqueira, A. C. (2010). Pais por adoção: A adoção na perspectiva dos casais em fila de espera. Psicologia: Teoria e Prática, 12(2), 200-216. Recuperado de: http://editorarevistas.mackenzie.br/index.php/ptp/article/view/2208

Instituto Brasileiro de Geografia e Estatística. (2010). Censo demográfico. Brasília, IBGE.

Lamb, M. E. (2012). Mothers, fathers, families, and circumstances: Factors affecting children's adjustment. Applied Developmental Science, 16(2), 98-111. doi: $10.1080 / 10888691.2012 .667344$

Leão, F. E., Porta, D. D., Pauli, C. G., Antoniazzi, M. P., \& Siqueira, A. C. (2017). Reflexões Teóricas sobre Maternidade e Adoção no Contexto da Monoparentalidade Feminina. Pensando famílias, 21(2), 45-59. Recuperado de: http://pepsic.bvsalud.org/pdf/penf/v21n2/v21n2a05.pdf

Machado, L. V., Ferreira, R. R., \& Seron, P. C. (2015). Adoção de crianças maiores: Sobre aspectos legais e construção do vínculo afetivo. Estudos Interdisciplinares em Psicologia, 6(1), 65-81. doi: 10.5433/2236-6407.2015v6n1p65

Mannis, V. S. (1999). Single mothers by choice. Family Relations, 48(2), 121-128. doi: $10.2307 / 585075$

Maux, A. A. B., \& Dutra, E. (2010). A adoção no Brasil: Algumas reflexões. Estudos $e$ Pesquisas em Psicologia, 10(2), 356-372. Recuperado de: http://pepsic.bvsalud.org/pdf/epp/v10n2/v10n2a05.pdf

Merçon-Vargas, E. A. (2012). A experiência de convivência em adoção nacional e internacional: Aspectos macrossistêmicos e processos proximais (Dissertação de Mestrado). Programa de Pós-Graduação em Psicologia, Universidade Federal do Espírito Santo, Vitória, Brasil. Recuperado de http://repositorio.ufes.br/handle/10/3082

Oliva, A. D., Pugliese, R., \& Cindra, E. (2018). Reflexões sobre algumas crenças parentais e práticas de cuidado. In. L. F. Pêssoa, D. M. L. F. Mendes, \& M. L. Seild-de-Moura 
(Eds.). Parentalidade: Diferentes Perspectivas, evidências e experiências (pp. 174199). Curitiba: Editora e Livraria Appris.

Patias, N. D., Siqueira, A. C., \& Dias, A. C. G. (2013). Práticas educativas e intervenção com pais: A educação como proteção ao desenvolvimento dos filhos. Mudanças Psicologia da Saúde, 21(1), 29-40. doi: 10.15603/2176-1019/mud.v21n1p29-40

Pena, M. (2016). La integración de niños y niñas a famílias adoptivas en argentina, conexiones legítimas. Revista Lationoamericana de Ciencias Sociales, Niñez y Juventud, 14(1), 445-461. doi: 10.11600/1692715x.14130130415

Pêssoa, L. F., \& Rosa, J. M. (2018). Reflexões sobre a parentalidade e as transformações nas configurações familiares. In. L. F. Pêssoa, D. M. L. F. Mendes, \& M. L. Seild-deMoura (Eds.). Parentalidade: Diferentes Perspectivas, evidências e experiências (pp. 117-139). Curitiba: Editora e Livraria Appris.

Portugal, A., \& Isabel, A. M. (2013). A comunicação parento-filial: Estudo das dimensões comunicacionais realçadas por progenitores e por filhos. Psicologia: Reflexão e Crítica, 26(3), 479-487. doi: 10.1590/S0102-79722013000300007

Ribeiro, J. M. L. (2012). Uso da palmada como ferramenta pedagógica no contexto familiar: Mania de bater ou desconhecimento de outra estratégia de educação? Pesquisas $e$ Práticas Psicossociais, 7(1), 52-58. Recuperado de https://www.ufsj.edu.br/portal2repositorio/File/revistalapip/Volume7_n1/Ribeiro.pdf

Rúbio, M. I. J., \& Pérez, F. V. (2012). Madres solteras por elección: Representaciones sobre la fecundación sexual como vía de acceso a la maternidade. Revista de Antropología Chilena, 44(4), 717-731. doi: 10.4067/S0717-73562012000400012

Santos, Y. G. S., Scorsolini-Comin, F., \& Santos, M. A. (2013). Homoparentalidade masculina: Revisão a produção científica. Psicologia: Reflexão e Crítica, 26(3), 572-5 82. doi: 10.1590/S0102-79722013000300017

Schettini, S. S. M. (2007). Filhos por adoção: Um estudo sobre o seu processo educativo em famílias com e sem filhos biológicos. (Dissertação de Mestrado). Psicologia Clínica, Universidade Católica de Pernambuco, Recife, Brasil. Recuperado de http://tede2.unicap.br:8080/handle/tede/234

Shireman, J. F., \& Johnson, P. R. (1985). Single-parent adoptions: A longitudinal study. Children and Youth Services Rewiew, 7(4), 321-334. doi: 10.1016/S01907409(85)80005-0 
Simões, S. C. C., Farate, C., Soares, I., \& Duarte, J. (2013). Predição de apego de crianças em função do estilo educativo materno e do tipo de família. Psicologia: Reflexão $e$ Crítica, 26(1), 168-176. doi: 10.1590/S0102-79722013000100018

Souza, R. P., \& Miranda, V. R. (2009). Adoção: Considerações histórico-sociais, psicológicas e jurídicas. In M. C. N. Carvalho, \& V. R. Miranda (Orgs), Psicologia jurídica: temas de aplicação (pp. 79-92). Curitiba: Juruá.

Toni, C. S. T., \& Hecavei, V. A. (2014). Relações entre práticas educativas parentais e rendimento acadêmico em crianças. Psico, 19(3), 511-521. doi: 10.1590/141382712014019003013

Tudge, J. R. H., \& Freitas, L. B. L. (2012). Parentalidade: Uma abordagem ecológico-cultural. In C. A. Piccinini, \& P. Alvarenga (Orgs), Maternidade e paternidade: A parentalidade em diferentes contextos (pp. 171-196). São Paulo: SP, Casa do Psicólogo.

Wade, S. M. (2004). Parenting influences on intellectual development and educational achievement. In M. Hoghughi, \& N. Long (Eds), Handbook of parenting: Theory and research for practice (pp. 198-212). London: Sage.

Walsh, F. (2016). Diversidade e complexidade nas famílias do século XXI. In F. Walsh (Eds.), Processos normativos da família: diversidade e complexidade (4a ed., pp. 327). Porto Alegre: Artmed.

\section{Endereço para correspondência}

\section{Carolina Monteiro Biasutti}

Universidade Federal do Espírito Santo

Prédio Professor Lídio de Souza

Avenida Fernando Ferrari, 514, Goiabeiras, Vitória - ES, Brasil. CEP 29075-910

Endereço eletrônico: psicarolinabiasutti@gmail.com

\section{Célia Regina Rangel Nascimento}

Universidade Federal do Espírito Santo

Prédio Professor Lídio de Souza

Avenida Fernando Ferrari, 514, Goiabeiras, Vitória - ES, Brasil. CEP 29075-910

Endereço eletrônico: celiarrn@gmail.com

\section{Cláudia Patrocinio Pedroza Canal}

Universidade Federal do Espírito Santo

Prédio Professor Lídio de Souza

Avenida Fernando Ferrari, 514, Goiabeiras, Vitória - ES, Brasil. CEP 29075-910

Endereço eletrônico: claudia.pedroza@ufes.br 
Recebido em: 14/05/2019

Reformulado em: 01/07/2020

Aceito em: 14/07/2020

\section{Notas}

* Mestre (bolsista FAPES) e Doutoranda (bolsista CNPq) do Programa de Pós-Graduação em Psicologia, da Universidade Federal do Espírito Santo.

** Profa. Dra. do Departamento de Psicologia e do Desenvolvimento e do Programa de Pós-Graduação em Psicologia da Universidade Federal do Espírito Santo.

*** Profa. Dra. do Departamento de Psicologia e do Desenvolvimento e do Programa de Pós-Graduação em Psicologia da Universidade Federal do Espírito Santo.

Financiamento: Artigo oriundo da dissertação de Mestrado 'Parentalidade em Casos de Adoção Monoparental', da aluna Carolina Monteiro Biasutti, defendida em agosto de 2016 na Universidade Federal do Espírito Santo, sob financiamento da Fundação de Amparo à Pesquisa e Inovação do Espírito Santo - FAPES.

Este artigo de revista Estudos e Pesquisas em Psicologia é licenciado sob uma Licença Creative Commons Atribuição-Não Comercial 3.0 Não Adaptada. 